\title{
Three young patients with unusual causes of stroke
}

\author{
Udaya K. Ranawaka', A T Alibhoy ${ }^{2}$ and Jagath C. Wijesekera ${ }^{3}$
}

(Index words: Protein C deficiency, paroxysmal nocturnal haemoglobinuria, hyperhomocysteinaemia)

\section{Introduction}

Ischaemic stroke in the young may be associated with uncommon thrombophilic or atherogenic states. The recognition of such causes is important as they may require specific treatment. We report three young patients with ischaemic stroke associated with protein $\mathrm{C}$ deficiency (an inherited thrombophilia), paroxysmal nocturnal haemoglobinuria (an acquired thrombophilia) and hyperhomocysteinaemia (an atherogenic and thrombophilic state).

\section{Case 1}

A 29-year old man was seen with a sudden left hemiparesis. He had had three similar events previously with incomplete recovery. CT (computed tomography) scanning showed a right fronto-parietal infarct. Haematological and biochemical screening, vasculitic screening, echocardiography and carotid duplex scanning were normal. Thrombophilia testing performed 6 months after the stroke revealed protein C deficiency (35\% of normal level). He was started on long term warfarin.

\section{Case 2}

A 39-year of previously healthy man had right homonymous hemianopia of sudden onset. CT scanning showed a left occipital infarct. Biochemical and vasculitic screening, echocardiography and carotid duplex scanning were normal. Blood counts showed leucopaenia and thrombocytopaenia, but bone marrow biopsy was normal. Urine was positive for haemosiderin even though a history of haemoglobinuria was not present. A positive Ham's test confirmed paroxysmal nocturnal haemoglobinuria. Warfarin was commenced.

\section{Case 3}

A 31-year old man with an acute left cerebellar syndrome was noted to have hypertension at the age of 24 , a myocardial infarction at 27 , and a left cerebral infarct at 29 years. CT scanning showed a recent left cerebellar infarct and multiple old infarcts. Echocardiography showed hypokinetic segments with no intramural clots. Haematological and biochemical screening and carotid duplex scanning were normal. In view of the multiple vascular events, warfarin was commenced. He later developed an ischaemic right leg, and duplex scanning revealed multiple large artery occlusions in both lower limbs. The presence of ischaemic heart disease, multiple strokes and peripheral arterial disease all pointed to a premature atherosclerotic state. Urine homocysteine was positive and plasma homocysteine was elevated, confirming hyperhomocysteinaemia. He was treated with folic acid, pyridoxine and vitamin B12.

\section{Discussion}

Stroke is a devastating illness. Its impact is even greater when it affects the young. $12 \%$ of first ever strokes occur in 'young' patients (less than 45 years) (1). Unlike in older patients where causation is commonly related to hypertension, diabetes or heart disease, ischaemic stroke in the young are associated with unusual causes. Thrombophilic states and conditions predisposing to premature atherosclerosis are important among them.

Inherited thrombophilias result from deficiencies of naturally occurring anticoagulants (protein $C$, protein $S$, antithrombin III), or from functional resistance to them (activated protein $\mathrm{C}$ resistance) (2). Transmitted as an autosomal dominant trait, inherited protein $\mathrm{C}$ deficiency is not uncommon in heterozygote form, but symptomatic deficiency is rare (3). Protein C levels may be falsely low immediately after a thrombotic event, and it is important to perform testing after an interval of 3 to 6 months (3). Treatment is with lifelong anticoagulation.

Paroxysmal nocturnal haemoglobinuria (PNH) is an intriguing condition where an acquired mutation leads to a clonal haemopoietic disorder. Mutation of the PIG-A gene on the X-chromosome results in defective production of a membrane protein, rendering the affected cells vulnerable to complement mediated lysis $(4,5)$. Haematopoietic stem cells are affected, leading to excess haemolysis with haemoglobinuria, infections and thrombosis (6). PNH should be considered in all patients with thrombotic events and cytopaenias. Treatment is usually supportive, with anticoagulation after thrombotic events. PNH may undergo transformation to myeloproliferative or aplastic states (6), and the definitive treatment is bone marrow transplantation (4).

Hyperhomocysteinaemia is increasingly being recognised as an important risk factor for arterial disease (7). It is associated with both premature atherosclerosis and a prothrombotic state, acting via a number of mechanisms involving the arterial wall smooth muscles, endothelial cells, natural antioxidants and circulating anticoagulants $(8,9)$. Fasting plasma homocysteine levels of more than $10.2 \mu \mathrm{mol} / \mathrm{l}$ are associated with a doubling of vascular risk (7). Dietary methionine is metabolised to homocysteine, and folate, pyridoxine and vitamin B12 act as cofactors in this metabolic pathway. Inherited deficiency of the regulating enzymes or acquired deficiency of the cofactors leads to hyperhomocysteinaemia. A combination of folic acid, pyridoxine and vitamin B12 is effective in reducing the vascular risk $(9,10)$.

'Resident Neurologist, ${ }^{2}$ Senior Registrar and ${ }^{3}$ Neurologist, Institute of Neurology, National Hospital of Sri Lanka, Colombo. (Accepted 21 October 2000). 
Young patients with stroke without an obvious underlying cause should be evaluated for unusual and potentially treatable causes. Failure to detect and treat them leads to recurrent vascular events, as seen in two of our patients.

\section{References}

1. Martin PJ, Enevoldson TP, Humphrey PRD. Causes of ischaemic stroke in the young. Postgraduate Medical Journal 1997; 73: 8-16.

2. Cavenagh JD, Colvin BT. Guidelines for the management of thrombophilia. Postgraduate Medical Journal 1996; 72: 8794.

3. Markus HS, Hambley H. Neurology and the blood: haematological abnormalities in ischaemic stroke. Joumal of Neurology, Neurosurgery and Psychiatry 1998; 64: 150-9.

4. Hillmen P, Lewis SM, Bessler M, Luzzato L, Dacie JV. Natural history of paroxysmal nocturnal haemoglobinuria. New England Journal of Medicine 1995; 333: 1253-8.
5. Miyata T, Yamada N, Yoshiyasu I, Nishimura J, Takeda J, Kitani T et al. Abnormalities of PIG-A transcripts in granulocytes from patients with paroxysmal nocturnal haemoglobinuria. New England Journal of Medicine 1994; 330: 249-55.

6. Rotoli B, Luzzato. Paroxysmal nocturnal haemoglobinuria. Bailliere's Clinical Haematology 1989; 2: 113-36.

7. Graham IM, Daly LE, Refsum HM, Robinson K, Brattstrom LE, Uerland PM, et al. Plasma homocysteine as a risk factor for vascular disease: the European Concerted Action Project. Journal of the American Medical Association 1997: 227: 1775-81.

8. Hankey GJ, Eikelboom JW. Homocysteine and vascular disease. Lancet 1999; 354: 407-13.

9. McCully KS. Homocysteine, folate, vitamin B6 and cardiovascular disease. Journal of the American Medical Assoication 1998; 279: 392-3.

10. Rimm EB, Willet WC, Hu FB. Sampson L, Colditz GA, Manson $\mathrm{JE}$, et al. Folate and vitamin B6 from diet and supplements in relation to risk of coronary heart disease among women. Journal of the American Medical Association 1998; 279: 359-64.

\section{Doing away with history}

Although I do not approve of the Taliban's destruction of Buddhist statues, I find the outrage over it arrogant and hypocritical, especially when expressed by Europeans and Americans. After all, the whole world has suffered and continues to suffer from the destruction of natural and cultural riches by the industrialized nations. Our forefathers blindly sacked and eradicated the Mayan and Inca civilizations, enslaved Africans, humiliated Native Americans and imposed their religion, language and political systems on the peoples of the Southern Hemisphere. And it is the North American and European multinationals that, by way of their ever-growing financial power, continue to dictate economic and cultural choices and wreak ecological havoc on the rest of the world. Western colonialists are the real destroyers of cultural identity. I do not support the Taliban's policies especially with regard to women, but shame for the cultural crimes committed by my country and continent prevents me from joining the outrage over their demolition of idols.

Georges Pfeiffenschneider. Doing away with history. Newsweek April 16, 2001 (letter) 